\title{
Environmental Mitigation Possibility via Organic Farming: Lettuce Case Study
}

\author{
C. Wongwai, T. Mungcharoen, and R. Tongpool
}

\begin{abstract}
The contamination of toxic in agricultural food and environment are the concerned issue in Thailand because it could damage the agricultural land and health of people in the long time and it also take many time to recover. This study were studied the environmental impact of organic lettuce (Grand rapids) compared with the conventional lettuce. The study consider 8 impact categories: 1) Climate change, 2) Human toxicity, 3) Terrestrial ecotoxicity, 4) Freshwater ecotoxicity, 5) Water depletion, 6) Fossil depletion, 7) Freshwater eutrophication and 8) Marine eutrophication. The scope considers the material input production, transportation and emission from the farm .The result of this study shown that organic lettuce were lower impact than conventional lettuce in all impact categories especially the three toxicity issue. Therefore, the organic lettuce could be the solution way to mitigation the environmental impact from the conventional lettuce in Thailand.
\end{abstract}

Index Terms - Life cycle assessment, organic lettuce, Human toxicity, organic farming.

\section{INTRODUCTION}

Vegetables contain nutrition for human body. They are popular for vegetarian and health-loving people. However, the toxicity from synthetic pesticides and fertilizers used at agricultural farms can cause detrimental effects to consumers and farmers [1]. Moreover, using synthetic pesticides lead to environmental problems such as high consumption of non-renewable energy resource, loss of biodiversity, pollution of aquatic environment by nitrogen and phosphorus nutrients [2].

On the other hand, an organic agriculture sustains the health of soil, ecosystem and people. It relies on ecological processes, biodiversity and the cycles adapted to local conditions, rather than the use of inputs having adverse effects [3]. The general standard of organic agricultures prohibits the use of synthetic fertilizers, pesticides and hormones [4]. Therefore, the organic agriculture could be a promising way to solve contaminations and environmental impacts occurring from the conventional agriculture (a

Manuscript received November 12, 2013; revised January 20, 2014. This work was supported in part by the Thailand Graduate Institute of Science and Technology (TGIST), National Science and Technology Development Agency (NSTDA).

C. Wongwai is with the Advanced and Sustainable Environmental Engineering, Thailand Advanced Institute of Science and Technology and Tokyo Institute of Technology: TAIST - Tokyo Tech, Faculty of Engineering, Kasetsart University, Bangkok 10900, Thailand (e-mail: chompunut.pu@gmail.com).

T. Mungcharoen is with Faculty of Engineering, Kasetsart University, Bangkok 10900, Thailand (e-mail: thumrongrut@nstda.or.th).

R. Tongpool is with Life Cycle Assessment Lab, National Metal and Materials Technology Center, 114 Paholyothin Rd., Klong 1, Klong Luang, Pathumthani 12120 Thailand (e-mail: rungnapt@mtec.or.th). farming system that is not certified organic or organic in conversion [4]).

In 2011, Nemecek et al. [2] investigated the life cycle impacts of organic and integrated farming system. The result showed that, if the whole farm system was considered, the organic farming (OF) was superior or similar to integrated production (IP). OF had its main strength in better resource conservation. However, when a single crop was considered, some organic products showed higher environmental burdens than the IP.

Lettuces are the economic vegetables in Thailand especially the Grand rapids lettuce because it's high demand throughout the year. It can grow all year round especially in cool weather [5]. Maria G. A. Gunady et al. [6] studied the global warming potential from the productions of strawberries, romaine or cos lettuces, and button mushrooms. The result showed that the highest potential belongs to the lettuces because of intensive agricultural machinery operations and the packing house. Kumar Venkat [7] applied standard-base life cycle assessment to compare the cradle-to-farm gate greenhouse gas (GHG) emissions of 12 crop products grown in California using both organic and conventional methods. The result showed that the steady-state organic production caused higher emissions per kilogram of product than the conventional production in seven out of the 12 cases; these 7 cases included the organic lettuce which showed $39.8 \%$ higher GHG emission than the conventional lettuce. However, transitional organic production performed better, generating lower emission than the organic and even lower than the conventional in some cases. The result demonstrated that converting additional cropland to organic production could offer significant GHG reduction over the next few decades by increasing the soil carbon stocks during the transition from nonorganic to organic systems by adopting management practices without entirely switching to organic methods.

The aim of this study is to evaluate the environmental impacts of organic Grand rapids lettuce (Org.) and conventional Grand rapids lettuce (Conv.) using life cycle assessment method.

\section{Methodology}

\section{A. Goal}

This study compares environmental impacts of organic and conventional lettuce productions, as well as finds out causes of the impacts.

\section{B. Scope}

The scope of the study covers i) the manufacturing of materials and energy inputs (e.g. fertilizers, pesticides, 
electricity, and fossil fuel), ii) transportation of the inputs from production sites to farms and iii) the production of the lettuce at farms. The system boundary is shown in Fig. 1. The lettuce production process includes i) soil preparation, ii) planting, iii) cultivating and iv) harvesting, as shown in Fig. 2. The functional unit is 1 ton of lettuce.

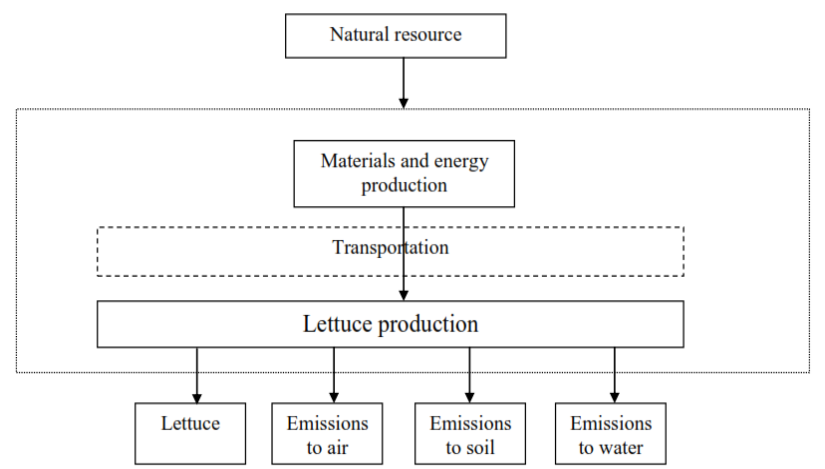

Fig. 1. System boundary in this study.

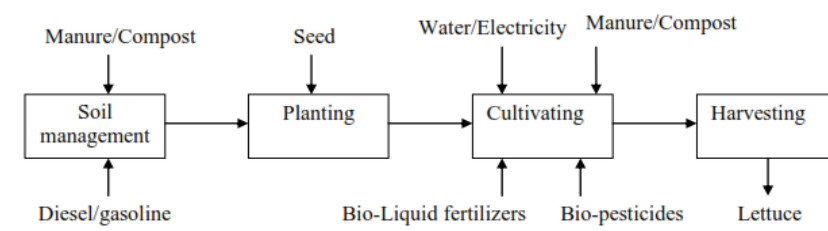

(a)

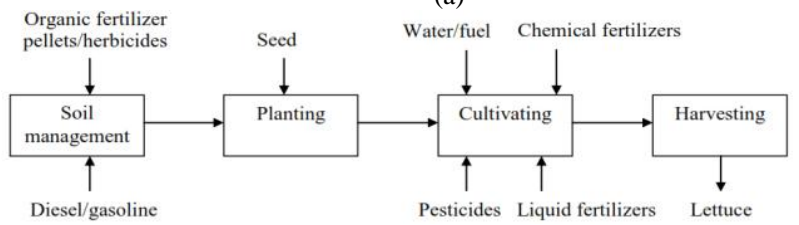

(b)

Fig. 2. Flow chart of lettuce production; (a) organic Grand rapids lettuce (Org) (b) conventional Grand rapids lettuce (Conv.)

\section{Life Cycle Inventory}

The life cycle inventory (LCI) data of the lettuce production was collected by interviewing the local farmers in Thailand using the questionnaires. The data of conventional lettuce was obtained from 10 farms in the central of Thailand which is the most growing area of lettuce [8]. The number of organic lettuce farming is much fewer than the conventional. Thus the data was obtained from 2 farms in the central, 1 farm from the north and 1 farm from the north-eastern of Thailand. As there are several kinds of salad vegetables produced at the farms, the data for the Grand rapids was allocated by weight of production.

The emissions to air, including $\mathrm{CH}_{4}, \mathrm{CO}, \mathrm{CO}_{2}, \mathrm{~N}_{2} \mathrm{O}$, $\mathrm{NH}_{3}, \mathrm{NMVOC}, \mathrm{NO}_{x}$ and particulate matter (PM) from fuel combustion and tillage operation at the farms were obtained by calculation, using emission factors of EMEP/EEA 2013 [9]. Emission of $\mathrm{N}_{2} \mathrm{O}$ from nitrogen fertilizer application was calculated, using emission factor of IPCC 2006 [10]. Emission of $\mathrm{NO}_{x}$ from nitrogen fertilizer application was calculated following Ecoinvent method [11]. Emissions to water include $\mathrm{N}$ leaching and runoff as well as $\mathrm{P}$ runoff. They are calculated using IPCC 2006 and Ecoinvent method [10], [11]. All pesticides and herbicides are assumed to be released to soil following Ecoinvent method [10]. The impacts from production of machinery and agricultural equipment are negligible because of their long lifetime. There is no waste management for the wastes from the lettuce production as the packages of fertilizers and pesticides were reused or sold out. In the case of the lettuce waste, it is left in the soil and used for animal feeding. The emissions from those left in the soil, such as $\mathrm{N}_{2} \mathrm{O}, \mathrm{NO}_{X}$ and $\mathrm{N}$ leaching, were calculated. The LCI data of organic and conventional lettuce productions are shown in Table I.

TABLE I: LIFE CYCLE INVENTORIES OF ONE TON OF LETTUCE PRODUCTION

\begin{tabular}{|c|c|c|c|}
\hline & Org. & Conv. & unit \\
\hline \multicolumn{4}{|l|}{ Input } \\
\hline Fuel & 2.573 & 17.561 & $\mathrm{~kg}$ \\
\hline Lime & 16.216 & 21.338 & $\mathrm{~kg}$ \\
\hline Gypsum & 0 & 1.873 & $\mathrm{~kg}$ \\
\hline \multicolumn{4}{|l|}{ Fertilizer } \\
\hline Organic Fertilizer & 1066.693 & 291.102 & $\mathrm{~kg}$ \\
\hline Mineral fertilizer & 0 & 118.445 & $\mathrm{~kg}$ \\
\hline \multicolumn{4}{|l|}{ Pesticides } \\
\hline Bacteria & 0.204 & 0.000255 & $\mathrm{~kg}$ \\
\hline Active ingredient & 0 & 0.0591 & $\mathrm{~kg}$ \\
\hline \multicolumn{4}{|l|}{ Herbicides } \\
\hline Active ingredient & 0 & 0.119 & \\
\hline \multicolumn{4}{|l|}{ Transport } \\
\hline Road & 23.422 & 39.4 & $\mathrm{tkm}$ \\
\hline Sea & 0.896 & 1701.568 & $\mathrm{tkm}$ \\
\hline \multicolumn{4}{|l|}{ Out put } \\
\hline Yield & 67.273 & 29.735 & $\begin{array}{l}\text { ton ha } \\
\text { year }^{-1}\end{array}$ \\
\hline Lettuce waste & 0.111 & 0.2 & ton \\
\hline \multicolumn{4}{|l|}{ Emission at farm } \\
\hline \multicolumn{4}{|l|}{ To air } \\
\hline \multicolumn{4}{|l|}{ Machinery combustion } \\
\hline $\mathrm{CH}_{4}$ & 0.00195 & 0.0199 & $\mathrm{~kg}$ \\
\hline $\mathrm{CO}$ & 0.733 & 7.503 & $\mathrm{~kg}$ \\
\hline $\mathrm{CO}_{2}$ & 8.166 & 55.857 & $\mathrm{~kg}$ \\
\hline $\mathrm{N}_{2} \mathrm{O}$ & 0.000274 & 0.00159 & $\mathrm{~kg}$ \\
\hline $\mathrm{NH}_{3}$ & 0.0000167 & 0.000100 & $\mathrm{~kg}$ \\
\hline NMVOC & 0.0392 & 0.439 & $\mathrm{~kg}$ \\
\hline $\mathrm{NO}_{X}$ & 0.0635 & 0.334 & $\mathrm{~kg}$ \\
\hline $\mathrm{PM}_{10}$ & 0.00326 & 0.0191 & $\mathrm{~kg}$ \\
\hline $\mathrm{PM}_{2.5}$ & 0.00326 & 0.0191 & $\mathrm{~kg}$ \\
\hline $\mathrm{SO}_{2}$ & 0.00799 & 0.0562 & $\mathrm{~kg}$ \\
\hline \multicolumn{4}{|l|}{ Fertilizer application } \\
\hline $\mathrm{CO}_{2}$ urea & 0 & 0.701 & $\mathrm{~kg}$ \\
\hline $\mathrm{N}_{2} \mathrm{O}$ & 0.174 & 0.438 & $\mathrm{~kg}$ \\
\hline $\mathrm{NO}_{X}$ & 0.0365 & 0.0920 & $\mathrm{~kg}$ \\
\hline $\mathrm{NH}_{3}$ & 0 & 2.138 & $\mathrm{~kg}$ \\
\hline NMVOC & 0 & $1.27 \mathrm{E}-07$ & \\
\hline \multicolumn{4}{|l|}{ Land preparation } \\
\hline $\mathrm{PM}_{10}$ tractor & 0.02318919 & 0.05246369 & $\mathrm{~kg}$ \\
\hline \multicolumn{4}{|l|}{ Limestone application } \\
\hline $\mathrm{CO}_{2}$ & 7.135 & 9.389 & $\mathrm{~kg}$ \\
\hline \multicolumn{4}{|l|}{ To water } \\
\hline $\mathrm{N}$ leaching & 2.211 & 7.711 & $\mathrm{~kg}$ \\
\hline P leaching & 0.00774 & 0.0171 & $\mathrm{~kg}$ \\
\hline \multicolumn{4}{|l|}{ To soil } \\
\hline Active ingredient & 0 & 0.178 & $\mathrm{~kg}$ \\
\hline
\end{tabular}


The inputs and transportations used in the productions were traced back to natural resource consumption and emissions of the upstream processes, using the database of Thailand and Ecoinvent as shown in Table II. Therefore the assessment scope is cradle to farm gate.

TABLE II: THE SOURCE OF SECONDARY DATA

\begin{tabular}{ll}
\hline \hline Inputs & Source of background data \\
\hline Fuel & Thai national LCI database \\
Lime and Gypsum & Ecoinvent system process \\
Fertilizers & Ecoinvent system process \\
Electricity & Thai national LCI database \\
Pesticides and & Ecoinvent system process \\
herbicides & \\
Transportation & Thai national LCI database \\
Road & Ecoinvent system process \\
Sea & \\
\hline \hline
\end{tabular}

\section{Impact Assessment}

After the LCI were obtained, the classification, and characterization methods of $\operatorname{ReCiPe} \operatorname{Midpoint}(\mathrm{H})$ were applied via Simapro7.3.3 software. Eight impact categories were assessed in this study: 1) Climate change, 2) Human toxicity, 3) Terrestrial ecotoxicity, 4) Freshwater ecotoxicity, 5) Water depletion, 6) Fossil depletion, 7) Freshwater eutrophication and 8) Marine eutrophication.

\section{RESULT AND DISCUSSION}

\section{A. Environmental Impact Assessment}

The result of impact assessments are shown in Fig. 3. The impact contributors of each categories were grouped into 7 components: 1) fuel production (shown as Fuel), 2) lime and gypsum production (shown as Lime and Gypsum), 3) fertilizers production (shown as Fertilizers), 4) electricity production (shown as Electricity), 5) Pesticides and herbicides production(shown as Pesticides and herbicides), 6) transportation operation (shown as Transportation) and 7) environmental burden taking place at the farms which were irrigation water, emissions from fertilizers application and fuel combustion (shown as Burden at farm).

It can be seen from Fig. 3 that the environmental impacts from the Organic lettuce (Org.) were lower than the Conventional lettuce (Conv.) in all impact categories, especially in the categories of Human toxicity, Terrestrial ecotoxicity and Freshwater ecotoxicity. The "Burden at farm" was more than $70 \%$ of the total impacts in the categories of Terrestrial ecotoxicity, Freshwater ecotoxicity, Water depletion, and Marine eutrophication.

More than half of the Climate change came from the fertilizer production. Burden at farm shared relatively large impacts which were $28 \%$ for Org. and $44 \%$ for Conv.

Fertilizers and Burden at farm contributed $36 \%$ and $61 \%$ for Conv., respectively, in the category of Human toxicity.

In the case of Water depletion category, Burden at farm showed relatively large contributions, which were $89 \%$ for Org. and $99.7 \%$ for Conv. There are $10 \%$ contributions from fertilizers in Org. because water was used to prepare organic fertilizers such as the compost, manure and bio-liquid fertilizers.

In Fossil depletion category, fertilizers used in Conv. shared the highest contribution, followed by the fuel and transportation, respectively. In the case of Org., electricity showed relative large contribution.

In Freshwater eutrophication category, fertilizers used in Conv. shared the highest contribution, follow by Burden at farm. In case of Org., Burden at farm showed the highest contribution.

In case of Marine eutrophication, Burden at farm showed relative large contributions which were $99 \%$ for Org. and $98 \%$ for Conv.

Many studies have shown that, compared to a conventional farming, an organic farming gave lower yield and used higher energy and fertilizer consumption [2], [7]. The results in this study were opposite. The yield of organic lettuce in this study was more than two times higher than the conventional lettuce (As shown in Table I). In addition, the fossil fuel consumption of Org. was lower. However there were burdens from the electricity in this study because the electricity use for water pump. In the study of Kumar [7], the GHG emission for Organic lettuce was $0.268 \mathrm{~kg} \mathrm{CO} 2 \mathrm{eq} / \mathrm{kg}$ lettuce which is similar to the Organic lettuce in this study $\left(0.238 \mathrm{~kg} \mathrm{CO} \mathrm{CO}_{2} \mathrm{eq} / \mathrm{kg}\right.$ organic lettuce). However, the GHG emission from the Conv. in this study $\left(421 \mathrm{CO}_{2} \mathrm{eq} / \mathrm{kg}\right)$ was much higher than that reported by Kumar $(190 \mathrm{~kg} \mathrm{CO} 2 \mathrm{eq} / \mathrm{kg})$. The reason for the higher emission came from the use of a large amount of fertilizers.

In the case of Human toxicity, Terrestrial ecotoxicity and Freshwater ecotoxicity, the results were consistent with Nemecek's study [2] that these three impact potentials of the conventional were much higher than the organic. The main causes for the impact in Human toxicity category were i) fertilizer production which caused the release of heavy metal to soil and ii) emissions of pesticides and herbicides to soil at farms. The main cause for Terrestrial and Freshwater ecotoxicity is emissions of pesticides and herbicides to soil at farms. Therefore reduction of fertilizers, pesticides and herbicides should be paid attention.

In the Water depletion category, the conventional consumed $666 \mathrm{~m} 3$ which was 1.7 times higher than the organic (388 m3). This is consistent with Rich Wood et al.'s study [12].

In Fossil depletion category, the impact from energy usage (fuel and electricity) in the Org. was slightly lower than the Conv. The Org. used electricity for water pump ( $7.78 \mathrm{~kg}$ oil eq/ton Org.) and fuel for tillage and spraying ( $3 \mathrm{~kg}$ oil eq/one ton Org.) while the Conv. used fuel only for water pump, tillage, and sprayer (22 kg oil eq/ ton Conv.). The main reason for the difference of the environmental performance of Org. and Conv. lettuce was the use of organic and mineral fertilizers. Mineral fertilizers require synthetic chemicals and fossil resources, as well as release heavy metals to environment, during the production. Moreover, it has to be transported from oversea to Thailand.

In case of Freshwater eutrophication and Marine eutrophication, the impact of Org. was lower in both categories. The main cause for impact in Freshwater 
eutrophication category was mineral fertilizer production which caused high phosphate release into water. The main cause for impact in Marine eutrophication was emissions of fertilizer to water at farms. This result was consistent with the DOC experiment of Nemecek's study [2].

Although the organic lettuce production used higher amount of organic fertilizers which was the source of high $\mathrm{N}_{2} \mathrm{O}$ emission, the environmental impacts of the conventional lettuce production from the use of mineral fertilizers and pesticides were more evident. Therefore, to mitigate the environmental impacts of Grand rapids lettuce production, organic farming is an attractive solution.

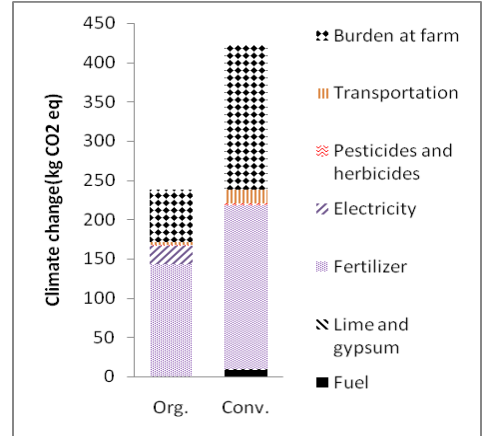

(a)

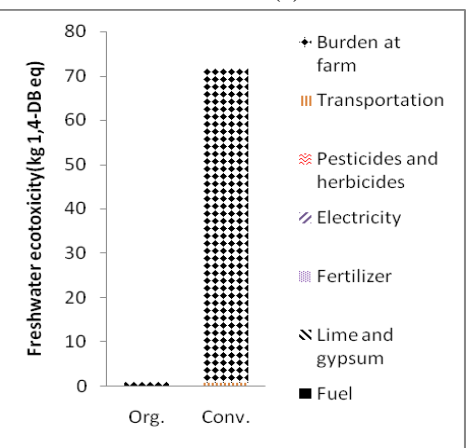

(d)

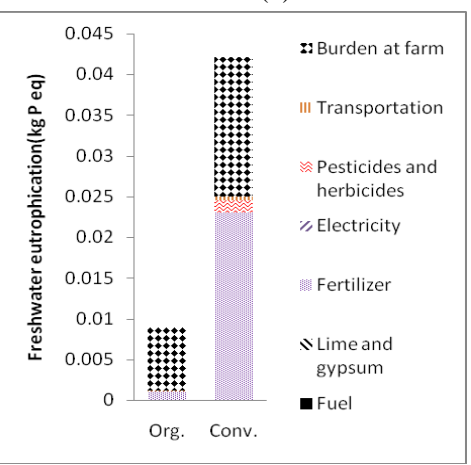

(g)

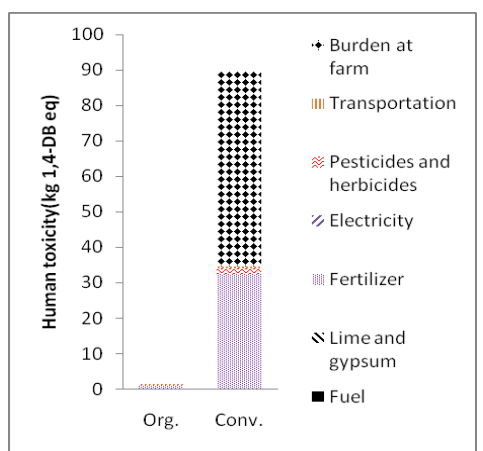

(b)

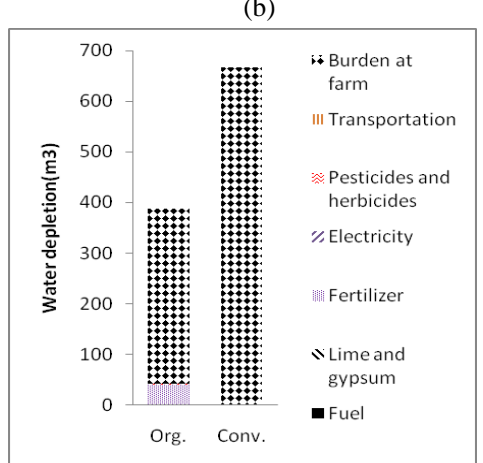

(e)

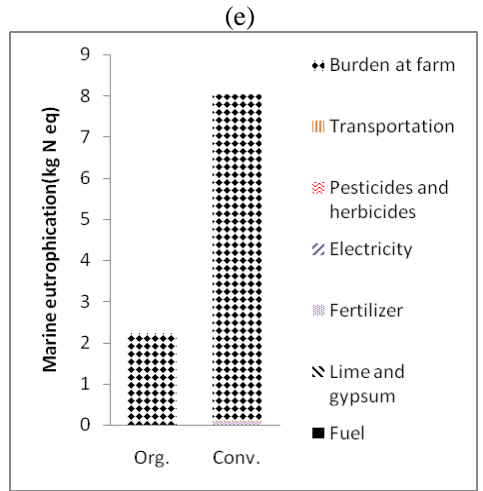

(h)
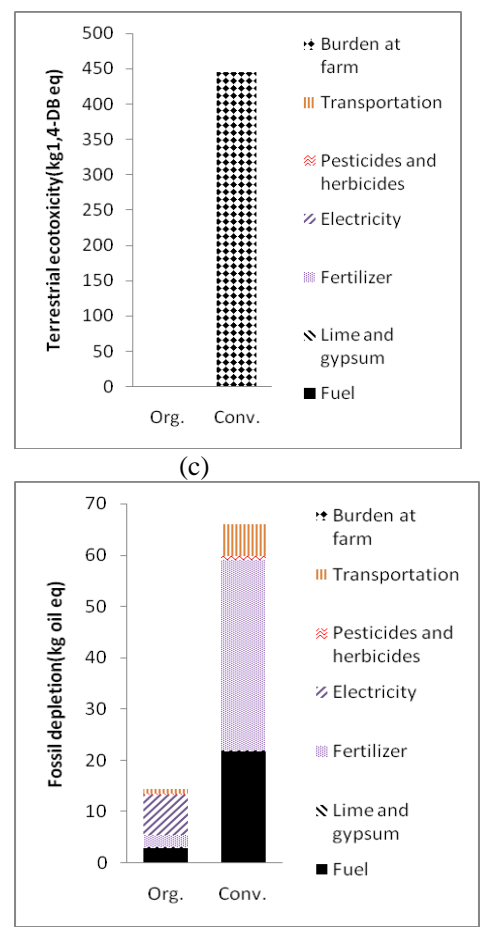

(f)

Fig. 3. Impact assessment of 1 ton of Grand rapids organic lettuce (Org.) and Grand rapids conventional lettuce (Conv.) in the categories of (a) Climate change, (b) Human toxicity, (c) Terrestrial ecotoxicity, (d) Freshwater ecotoxicity, (e) Water depletion, (f) Fossil depletion, (g) Freshwater eutrophication and (h) Marine eutrophication.

\section{CONCLUSIONS}

We found that the yield of organic Grand rapids lettuce was more than two times higher than the conventional Grand rapids lettuce. The environmental impacts of organic Grand rapids was lower than the conventional Grand rapids in all impact categories. The Climate change of the organic Grand rapids was about half of the conventional Grand rapids. The Human toxicity, Terrestrial ecotoxicity and Freshwater ecotoxicity of organic Grand rapids were much lower because the synthetic pesticides were not applied. Water depletion for organic Grand rapids production was $42 \%$ lower than conventional Grand rapids. Fossil depletion due to organic Grand rapids were $78 \%$ lower than conventional Grand rapids. Freshwater eutrophication and Marine eutrophication of organic Grand rapids was $79 \%$ and $72 \%$ lower than conventional Grand rapids, respectively. The environmental performance of organic Grand rapids could be improved even better if the compost usage was reduced.

\section{ACKNOWLEDGMENT}

C.Wongwai thanks 14 farmers in Thailand who gave the information on lettuce cultivation, Department of agriculture, Agricultural Extension office and Organic Agriculture Certification Thailand who gave suggestions on the technical information.

This study was accomplished through the funding of National Science and Technology Development Agency (NSTDA) Thailand, Thailand Advanced Institute of Science and Technology and Tokyo Institute of Technology (TAIST-Toyko Tech), and Faculty of Engineering, Kesetsart University. 


\section{REFERENCES}

[1] The Effect of Pesticide on Thai People Health, 2012.

[2] T. Nemecek, D. Dubois, O. Huguenin-Elie, and G. Gaillard, "Life cycle assessment of Swiss farming systems: I. Integrated and organic farming," Agricultural Systems, vol. 104, no. 3, pp. 217-232, 2011.

[3] IFOAM, Definition of Organic Agriculture, 1972.

[4] Organic Standard 2012, Organic Agriculture Certification, Thailand, 2012 .

[5] Vegetable Stories, Publication Department of Agriculture, 2006.

[6] M. G. A. Gunady, W. Biswas, V. A. Solah, and A. P. James, "Evaluating the global warming potential of the fresh produce supply chain for strawberries, romaine/cos lettuces (Lactuca sativa), and button mushrooms (Agaricus bisporus) in Western Australia using life cycle assessment (LCA)," Journal of Cleaner Production, vol. 28, pp. 81-87, 2012.

[7] K. Venkat, "Comparison of twelve organic and conventional farming systems: A life cycle greenhouse gas emissions perspective," Journal of Sustainable Agriculture, vol. 36, no. 6, pp. 620-649, July 1, 2012.

[8] PhuangThip Report of lettuce Thai, Department of Agriculture, 2012.

[9] EMEP/EEA Air Pollutant Inventory Guidebook, 2013.

[10] IPCC, IPCC Guidelines for National Greenhouse Gas Inventories, 2006.

[11] T. Nemecek and T. Kägi, Life Cycle Inventories of Agricultural Production Systems Swiss Centre for Life Cycle Inventories, Zurich, 2007.

[12] R. Wood, M. Lenzen, C. Dey, and S. Lundie, "A comparative study of some environmental impacts of conventional and organic farming in Australia," Agricultural Systems, vol. 89, no. 2-3, pp. 324-348, 2006.

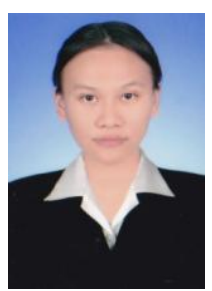

C. Wongwai was born in Thailand on October 13, 1989 She got the bachelor's degree of engineering from Silpakorn University, Nakorn Pathom, Thailand, 2012.

She used to have training experience in Clariant Masterbatches (Thailand) Ltd. From March 21, 2011 to May 20, 2011. She is now undertaking master degree under a collaboration program between Japan (Tokyo Institute of Technology) and Thailand (Kasetsart university, and National Science and Technology
Development Agency).

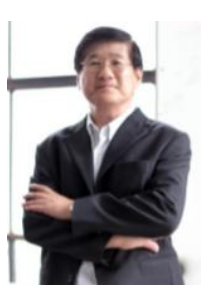

T. Mungcharoen was born in Thailand. He got the B.Eng. Hons. in chemical engineering from Chulalongkorn University, Thailand and M.Sc., Ph.D.in chemical engineering from University of Texas at Austin, USA.

Now, he is an associate professor at Kasetsart University and also the director of Sustainable Environment Program and chairman of Energy and Environment Cluster, National Science and Technology Development Agency.

Dr. Mungcharoen's research area is in cleaner technology, life cycle assessment, eco-design, process safety and risk analysis. He is among the key persons who have started the Thai Life Cycle Inventory Database project and the Thai Carbon Footprint project. He sits in an executive board of the Asia Pacific Roundtable on Sustainable Consumption and Production. He has more than 180 scientific publications.

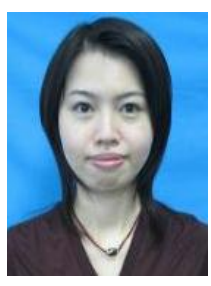

R. Tongpool was born in Thailand. She got B.Sc. in chemistry from Kasetsart University, Thailand in 1995, and M.Sc. in metallic and ceramic materials from University of Manchester Institute of Science and Technology (UMIST), UK in 1996, and PhD (Gas sensing behaviour based on $\mathrm{CuO}$ and $\mathrm{ZnO}$ heterocontacts) from University of Manchester Institute of Science and Technology (UMIST), UK in 2000.

Now, she is a principle researcher in the Department of LCA Lab, Division of Environmental Research Unit, National Metal and Material Technology Center, National Science and Technology Development Agency.

Dr. Tongpool's research area is in eco product development and production process improvement. And her research project is in establishment of Thai national life cycle inventory database, LCA of ecoproduct. 